\title{
Use of the Psychosocial Index: A Sensitive Tool in Research and Practice
}

\author{
Antonio Piolanti ${ }^{a}$ Emanuela Offidani ${ }^{c}$ Jenny Guidi ${ }^{a}$ Sara Gostoli ${ }^{a}$ \\ Giovanni A. Fava ${ }^{a, d}$ Nicoletta Sonino ${ }^{b, d}$ \\ ${ }^{a}$ Department of Psychology, University of Bologna, Bologna, and ${ }^{b}$ Department of Statistical Sciences, University \\ of Padova, Padova, Italy; ' Center for Integrative Medicine, Weill Cornell Medical College, New York, N.Y., and \\ ${ }^{\mathrm{d}}$ Department of Psychiatry, University at Buffalo, Buffalo, N.Y., USA
}

\section{Key Words}

Psychosocial Index · Stress · Allostatic load · Well-being ·

Anxiety - Depression · Illness behavior · Quality of life ·

Clinimetrics $\cdot$ Patient-reported outcomes

\begin{abstract}
Background: The Psychosocial Index (PSI) is a self-rating scale based on clinimetric principles that is simple to use in a busy clinical setting. It can be integrated by observer-rated clinical judgment, providing a first-line, comprehensive assessment of stress, well-being, distress, illness behavior, and quality of life. By calculation of scores, it can be used for conventional psychological measurements. Its clinical applications and clinimetric properties are reviewed. The present version of the PSI has been slightly revised. In addition, a modified version for use in adolescents and young adults (PSI-Young; PSI-Y) is also included. Methods: Articles that involved the use of the PSI were identified by searching the Web of Science database from 1998 to February 2016 and by a manual search of the literature. Results: A total of 20 studies reporting results from the use of PSI were included. The PSI has been employed in various clinical populations in different countries and showed high sensitivity. It significantly discriminated varying degrees of psychosocial impairment
\end{abstract}

\section{KARGER}

E-Mail karger@karger.com www.karger.com/pps in different populations. When subjects were identified by categorical criteria (presence of allostatic overload, psychosomatic syndromes, psychiatric disorders), the PSI scores were significantly different across subgroups. Conclusions: In clinical practice, scanning the list of symptoms allows clinicians to assess rapidly which symptoms and problems are perceived as most troublesome. In research settings, the use of scores makes the PSI a valid and sensitive tool in differentiating levels of psychosocial variables among groups.

두 2016 S. Karger AG, Base

\section{Introduction}

The Psychosocial Index (PSI) was introduced by Sonino and Fava [1] in 1998 mainly to provide clinicians with a simple screening tool for stress and other psychosocial dimensions in a busy clinical practice. By the evaluation of scores, it can be employed in research settings as well. It was developed according to clinimetric principles. The domain of clinimetrics is concerned with quantitative methods in the collection and analysis of clinical phenomena, such as type, severity and sequence of symptoms, problems of functional capacity, and reason for medical decisions, with emphasis on clinical judgment (c) 2016 S. Karger AG, Basel

0033-3190/16/0856-0337\$39.50/0
Nicoletta Sonino, MD

Department of Statistical Sciences, University of Padova Via Battisti 241

IT-35121 Padova (Italy)

E-Mail nicoletta.sonino@unipd.it 
[2-8]. The clinimetric criteria for evaluating the clinical validity of a scale differ from those of the standard psychometric analyses $[4,9]$. An essential difference is concerned with the discrimination properties (responsiveness/sensitivity) of an index, defined as the ability to differentiate between patients and controls. Unlike in psychometrics, homogeneity of components is not requested and single items may be weighed in different ways. What matters is the capacity of an index to discriminate between different groups of subjects and to reflect changes in experimental settings such as drug trials. In psychometrics, the same properties that give a scale a high score for homogeneity may obscure its ability to detect change, and redundant scale items may increase homogeneity but decrease sensitivity [4]. A high correlation is often regarded as evidence that the two scales measure the same factor. However, a high correlation does not indicate similar sensitivity: a common content of two scales may insure a high positive correlation between them, but the items they do not share may be important in determining their sensitivity [4]. A test of sensitivity is provided by the capacity of an index to discriminate between subgroups of subjects with the same disease (e.g., inpatients and outpatients with depression) [10].

Based on insights derived from studies performed in the past two decades, we here report a slightly modified version of the PSI and review the available data concerning its clinimetric properties and clinical applications.

\section{Description of the PSI}

This self-rating questionnaire (Appendix 1) includes 55 items, most of which are derived from previously validated instruments. Thirty-five items (1-20 and 37-51) were selected from the 118 of Kellner's Screening List for Psychosocial Problems [11], eliminating all sources of redundancy. They constitute the sociodemographic and clinical data section, the psychological distress scale and part of the stress scale. The latter has been integrated with 10 items (21-30) derived from the Wheatley Stress Profile [12]. Six questions (31-36) were derived from Ryff's Psychological Well-Being scales [13] and constitute the wellbeing section. Three questions (52-54) were selected from Kellner's Illness Attitude Scales $[14,15]$ and compose the abnormal illness behavior scale.

The following domains are covered:

(a) Sociodemographic and clinical data: this part (items 1-12) includes largely routine information about medical and psychiatric history, the patient's family, employment and habits. It may alert clinicians to some threats to health, such as alcohol or drug use. (b) Stress: this section (items 13-20 and 22-30) is an integration of both perceived and objective stress, life events and chronic stress. It consists of 17 questions with a total score ranging from 0 to 17 . These questions contain essential information for case identification of allostatic overload [16].

(c) Well-being: this section (items 31-36) covers different areas of well-being, i.e., positive relations with others (items 31, 32), environmental mastery (items 33, 34) and autonomy (items 35,36), with a score ranging from 0 to 6.

(d) Psychological distress: this section (items 37-51) consists of a checklist of symptoms addressing sleep disturbances, somatization, anxiety, depression and irritability. The total score may range from 0 to 45 . Questions 37-40 refer to sleep disturbances (range 0-12) and may also be scored separately from the other questions.

(e) Abnormal illness behavior: it allows the assessment of hypochondriacal beliefs and bodily preoccupations (items 52-54). The total score may range from 0 to 9.

(f) Quality of life (item 55): a simple direct question on quality of life is included, following the recommendation of Gill and Feinstein [17]. The score ranges from 0 to 4. The scores concerned with psychological well-being $(0-6)$ and quality of life $(0-4)$ can be added for obtaining a global well-being score (0-10).

The self-rating questionnaire (Appendix 1) provides a dimensional assessment of psychosocial features. Some questions involve specific responses, most require a yes/ no answer, while others are rated on a Likert scale $(0-3$, from 'not at all' to 'a great deal'); 1 item, quality of life, has 5 possible choices, from excellent to awful. For detailed scoring instructions, see Appendix 3. The PSI is not designed to calculate a total score.

A 51-item modified version of the PSI has recently been developed for assessing psychosocial factors among adolescents and young adults up to 21 years of age (PSIYoung; PSI-Y), with particular reference to studying activities, educational setting, peer relationships, and family environment (see online suppl. table 1, 2; see www. karger.com/doi/10.1159/000447760 for all online suppl. material). It has been used in a study aimed at providing a psychological characterization of hyperandrogenic states among late adolescent and young women [18].

The observer rating of the PSI (Appendix 2), by visually scanning the patient self-rated responses, allows the clinician to evaluate the PSI subscales directly on a 5-point Likert scale. Observer-rating scores may range from highly stressful life to nonstressful life for stress; from excellent to absent for well-being; from incapacitating to ab- 
sent for psychological distress and abnormal illness behavior. Observer rating does not provide a total score. Question 55 on quality of life is self-rated by the patient, with no need for external judgment by the observer.

\section{Methods}

\section{Data Source}

Articles citing the original PSI reference [1] were identified by searching the Web of Science database, from 1998 to February 2016. In addition, potentially relevant papers were searched manually.

\section{Study Selection}

Two investigators (A.P. and E.O.) carried out the search independently; disagreements were resolved by consensus among raters and one senior investigator (N.S.). Articles were considered to be eligible if they reported research data with regard to administration of the PSI.

\section{Data Extraction}

Data were independently extracted with the use of a precoded form. The following data were extracted from the included studies: purpose of the study, number of subjects, design, tools administered and findings (online suppl. table 3 ).

\section{Results}

\section{Characteristics of Included Studies}

The literature search identified 37 relevant articles. Of these, 17 were excluded: 15 studies only cited the PSI and 2 were duplicates. A total of 20 investigations were included in the review (for a flow diagram of the search, see online suppl. fig. 1). Details of the 20 studies are summarized in online supplementary table 3 and the main findings are outlined here.

\section{Use for Clinical Assessment}

- The interrater reliability of the observer-rating part of the PSI (Appendix 2) was assessed in subjects with functional medical disorders evaluated by an internist and a psychiatrist. The PSI observer-rating part showed high interrater reliability, with intraclass correlation coefficients of 0.88 for rating stress, 0.94 for well-being, 0.89 for psychosocial distress, and 0.90 for illness behavior [1].

- The PSI was used to aid the clinical interview in three investigations concerned with the assessment of allostatic overload in the general population [19], in atrial fibrillation [20], and in congestive heart failure [21]. In these three studies, individuals who displayed allostat- ic overload were found to report significantly more psychological distress than subjects without allostatic overload. In another investigation [22], the determination of allostatic overload in healthy subjects was based on the responses to the PSI in conjunction with additional self-rated measures. This study showed that individuals with an allostatic overload differed from those without it in levels of some biological parameters [22].

- The PSI has been administered as a screening tool for psychosocial factors in a psychoneuroendocrinology clinic [23]. Data gathered from the PSI were used to evaluate the need of patients for further psychological assessments and to plan therapeutic strategies.

\section{Use of Self-Rating Scores}

The PSI consists of items of validated scales and its sections can thus be used for conventional psychological measurements.

- In clinical endocrinology, it detected significantly higher levels of stress and psychological distress, impaired well-being and maladaptive illness behavior in patients with pituitary disease compared to healthy controls [24]. The sensitivity of the PSI was also confirmed when a population suffering from a wide range of endocrine conditions [25] was analyzed as to the presence of psychiatric disorders according to the DSM-IV [26] and/or psychosomatic syndromes according to the Diagnostic Criteria for Psychosomatic Research (DCPR) [27-29]. Psychological distress identified by semistructured research interviews was confirmed by PSI self-rated scores. Such findings were similar to those obtained in a community sample [30], where significantly higher scores in the scales of stress and psychological distress and significantly lower scores in well-being were found in subjects with DCPR syndromes compared to those without. In another study [31], hypertensive subjects with primary aldosteronism showed significantly higher levels of stress and psychological distress and lower levels of well-being as compared to normotensive controls. Furthermore, patients with primary aldosteronism displayed significantly higher scores on PSI stress compared to patients with essential hypertension. Finally, in a recent study [18], adolescent females affected by isolated clinical hyperandrogenism (i.e., hirsutism) reported significantly lower levels of PSI-Y well-being and quality of life compared to their healthy counterparts.

- As to blood pressure, the PSI was used to evaluate the influence of psychosocial factors on changes in day- 
time/nighttime blood pressure rhythm in normotensive and hypertensive subjects [32]. In this investigation, the items concerned with sleep disturbances were analyzed separately from the section of psychological distress. Patients with essential hypertension who had no nocturnal fall in blood pressure had a significantly worse quality of sleep compared to those who had the blood pressure physiological decline. Further, there were significant correlations between the amount of stress and nocturnal blood pressure levels in subjects with normal blood pressure [32]. In another study on hypertensive subjects [33], participants were classified into three subgroups (affective disturbances, alexithymia, and somatization) according to a cluster analysis based on DSM-IV [26] and DCPR [27-29] diagnoses. The combined PSI score of stress and psychological distress discriminated among these subgroups. Patients in the somatization group reported the highest combined score and those in the alexithymia group showed the lowest score.

Subjects with medically unexplained syncope showed significantly higher levels of PSI psychological distress and lower levels of psychological well-being, as compared to individuals with vasovagal syncope [34]. This finding is consistent with previous studies $[35,36]$.

- In cardiology, a longitudinal study [37] evaluated the psychological status of patients who underwent coronary artery bypass grafting at 1 month and at 6-8 years after surgery. The PSI section of abnormal illness behavior sensitively detected a decrease in worry about physical conditions when the acute phase of the illness abated. In patients with recent myocardial infarction who participated in a cardiac rehabilitation program [38], combined PSI scores did not predict subsequent coronary events (death, myocardial infarction, or angina pectoris). Among patients with congestive heart failure [39], participants with DCPR diagnoses had significantly higher scores on the PSI sections of stress and psychological distress compared to those with no diagnoses. In patients with an implantable cardioverter defibrillator [40], the PSI was used to monitor psychological variables up to 1 year of follow-up.

- Breast cancer survivors showed significantly higher levels of PSI psychological distress as compared to healthy controls reporting negative events other than cancer [41]. In addition, breast cancer survivors with a high posttraumatic growth score reported significantly less psychological distress compared to those with a low score. Posttraumatic growth is a feature that indicates positive changes in many life domains as a result of the personal, cognitive and emotional efforts in dealing with traumatic events [42].

- In the setting of a highly pathogenic avian influenza in Nigeria, people whose farms had suffered avian influenza H5N1 outbreaks had significantly higher PSI scores of abnormal illness behavior and stress than those whose farms had not been affected by the outbreak epidemics in poultry [43].

\section{Discussion}

The self-rating PSI may be employed in different ways: (a) as a screening tool in the setting of medical evaluation and interviewing; (b) it can be integrated with clinical judgment by applying a simple observer-rated score, and (c) by calculation of scores, it can be used for conventional psychological measurements [1]. In the studies that we have reviewed, all these modalities have been used.

In clinical assessment, using the PSI allows to scan the list rapidly to determine which psychological and social problems, and/or psychiatric symptoms the patient finds distressing. By simply scanning the answers, the clinician may understand the degree of stress, well-being, psychological distress, illness behavior and quality of life. It may provide preliminary ground for specific questions as to psychological distress during medical examination and interviewing, leading to diagnostic and therapeutic decisions or specialist referral $[1,23]$.

The simple observer-rating score, which emphasizes clinical judgment [4], may result particularly useful for clinical practice, due to the short time that is requested for this rating. These issues are all of considerable importance for primary care, where psychological distress is common but often remains undetected and inadequately managed [44].

The PSI has some unique properties compared to other scales that are available [3]. According to clinimetric principles, items that were included were selected on the basis of the amount of clinical information they carried. For instance, as to psychological distress, there are 4 items concerned with sleep (items 37-40, Appendix 1), that cover difficulties falling asleep, restless sleep, early morning awakening and feeling tired on waking up. These are 4 key areas in the determination of sleep quality $[45,46]$.

The specific contribution of the PSI as to main clinical domains deserves to be discussed. 


\section{Allostatic Load}

Due to its ability to provide a quick but comprehensive evaluation of stress, the PSI is a very suitable instrument for the screening of allostatic overload, especially in medical settings [20-22, 47]. Clinimetric criteria for the determination of allostatic overload include: (a) the presence of a stressor exceeding individual coping skills, and (b) clinical manifestations of distress, which may range from psychiatric to psychosomatic/subclinical symptoms, and from impairment in social and occupational functioning to decrease in well-being [16].

\section{Well-Being}

Stress, psychological distress and illness behavior may be linked to the individual's potential for coping and social support (well-being). Several studies have suggested that psychological well-being plays a buffering role in coping with stress and has a favorable impact on disease course $[13,45,48,49]$.

\section{Psychological Distress}

Psychological distress is strongly associated with medical conditions. Depression, in particular, may affect functioning, quality of life and health care utilization [50, 51]. However, there is emerging awareness that also psychological symptoms that do not reach the threshold of a psychiatric disorder may affect quality of life and entail pathophysiological and therapeutic implications [29].

\section{Illness Behavior}

The concept of illness behavior was introduced to indicate the ways in which given symptoms may be perceived, evaluated and acted upon at an individual level [52]. Illness behavior may greatly vary according to illness-related, patient-related and doctor-related variables and their complex interactions. In the past decades, important lines of research have been concerned with illness perception, frequent attendance of medical facilities, health-care-seeking behavior, treatment-seeking behavior, delay in seeking treatment, and treatment adherence [53-55]. According to this review, the questions on abnormal illness behavior helped to discriminate between subgroups [24, 43]. They might show high sensitivity in populations where hypochondriasis or functional medical disorders are predominant aspects [15].

\section{Quality of Life}

Since measures of disease status alone are insufficient to describe the burden of illness, it has been proposed that the evaluation of disease outcomes by the clinician be integrated with appraisal of health and quality of life by the patient $[56,57]$. A related aspect concerns patient-reported outcomes, any report coming directly from patients without interpretation by physicians or others about how they function or feel in relation to a health condition or its therapy $[58,59]$. The PSI provides a global measure of well-being integrated with that of quality of life. The evidence from the studies included in this review suggests that well-being and quality of life are compromised in patients with cardiovascular and endocrine disorders $[18$, $24,31,32,34]$.

Calculation of scores provides conventional psychological measurements. The findings suggest a high sensitivity of the PSI self-rating questionnaire. In all studies, the PSI displayed good sensitivity in discriminating between patients and controls. In particular, there were significant differences in stress, psychological distress and well-being between patients affected by endocrine disease, cardiovascular disorders, breast cancer and their matched healthy controls. In addition, the PSI discriminated between subjects with and without allostatic overload [19-22].

Another important clinimetric characteristic is incremental validity $[4,60]$ : each distinct aspect of measurement should deliver a unique increase in information in order to qualify for inclusion. Often a number of scales are used under the misguided assumption that nothing will be missed. On the contrary, violation of the concept of incremental validity leads to conflicting results [4]. Each of the five PSI sections yields an incremental increase in information that provides a comprehensive assessment of the main psychosomatic domains $[16,50,61]$, where elements of redundancy were eliminated.

In conclusion, the PSI constitutes a clinimetric tool of high clinical utility and allows a comprehensive, sensitive appraisal of psychosomatic domains in different populations.

\section{Disclosure Statement}

None of the authors has any conflicts of interest to declare. 
Appendix 1. PSI, revised version (modified from Sonino and Fava [1])

Self-rating items

NAME SURNAME

1. Date of birth: month year

2. Sex: day Male

3. Marital status:

Female

Single

Married

Divorced

Separated

Widowed

4. Occupation

How many hours do you work per week?

Occupation of spouse:

5. Have you ever been hospitalized?

YES

$\mathrm{NO}$

6. Please list illnesses, surgical operations and other treatments and give dates

7. Are you allergic to any drug or substances? If yes, specify

8. What medication are you taking at present?

9. Do you drink alcohol?

10. Do you smoke?

11. Do you take recreational drugs?

12. Do you drink coffee or tea? If yes, how many per day?

Did any of the following happen to you in the past year? (YES/NO)

13. Death of a family member

14. Separation from spouse or long-time partner

15. Recent change of job

16. Financial difficulties

17. Moving within the same city

18. Moving to another city

19. Legal problems

20. Beginning of a new relationship

Please answer the following questions (YES/NO)

21 Do you have a job?

If you have a job:

22. Are you satisfied with your work?

23. Do you feel under pressure at work?

24. Do you have problems with your colleagues at work?

If you do not have a job:

22. Are you retired or student?

23. Do you feel under pressure during the day?

24. Are you unable to find a job?

$\mathrm{NO}$

YES

$\mathrm{NO}$

YES

$\mathrm{NO}$

YES

YES

YES

YES

NO

$\mathrm{NO}$

$\mathrm{NO}$

NO

25. Do you have serious arguments with close relatives?

YES

$\mathrm{NO}$

26. Do you have serious arguments with other people?

YES

YES

YES

$\mathrm{NO}$

27. Has any close relative been seriously ill in the past year? If yes, specify:

28. Do you feel tension at home?

YES NO

YES NO

YES NO

YES NO

YES NO

YES NO

YES NO


29. Do you live by yourself?

30. Do you feel lonely?

31. Do you have anyone whom you can trust and confide in?

32. Do you get along well with people?

33. Do you often feel overwhelmed by the demands of everyday life?

34. Do you often feel you cannot make it?

35. Do you tend to be influenced by people with strong opinions?

36. Do you tend to worry about what other people think of you?

$\begin{array}{ll}\text { YES } & \text { NO } \\ \text { YES } & \text { NO } \\ \text { YES } & \text { NO } \\ \text { YES } & \text { NO } \\ \text { YES } & \text { NO } \\ \text { YES } & \text { NO } \\ \text { YES } & \text { NO } \\ \text { YES } & \text { NO }\end{array}$

Please describe any problems or difficulties you have had recently and indicate how much they have troubled you by marking the appropriate column

37. It takes a long time to fall asleep

38. Restless sleep

39. Waking too early and not being able to fall asleep again

40. Feeling tired on waking up

41. Stomach, bowel pains

42. Heart beating quickly or strongly without a reason

43. Feeling dizzy or faint

44. Feelings of pressure or tightness in head or body

45. Breathing difficulties or feeling of not having enough air

46. Feeling tired or lack of energy

47. Irritable

48. Sad or depressed

49. Feeling tense or 'wound up'

50. Lost interests in most things

51. Attacks of panic

52. Do you believe you have a physical disease but that doctors have not diagnosed it correctly?

53. When you read or hear about an illness, do you get similar symptoms?

54. When you notice a sensation in your body, do you find it difficult to think of something else?

55. How do you rate the quality of your life?

\begin{tabular}{|c|c|}
\hline at all & $\begin{array}{l}\text { Only a } \\
\text { little }\end{array}$ \\
\hline
\end{tabular}

Appendix 2. PSI, revised version (modified by Sonino and Fava [1])

Observer-rating scores

\begin{tabular}{|c|c|c|c|c|c|}
\hline \multirow[b]{2}{*}{$\underline{\text { Stress }}$} & \multicolumn{2}{|l|}{ Highly stressful life } & \multicolumn{2}{|l|}{ Stressful life } & \multirow{2}{*}{$\begin{array}{l}\text { Non-stressful life } \\
1\end{array}$} \\
\hline & 5 & 4 & 3 & 2 & \\
\hline & Excellent & Good & Fair & Poor & Absent \\
\hline Well-being & 5 & 4 & 3 & 2 & 1 \\
\hline & Incapacitating & Severe & Moderate & Slight & Absent \\
\hline Psychological distress & 5 & 4 & 3 & 2 & 1 \\
\hline & Incapacitating & Severe & Moderate & Slight & Absent \\
\hline Abnormal illness behavior & 5 & 4 & 3 & 2 & 1 \\
\hline
\end{tabular}




\section{How to score the PSI}

Stress: the scale includes 17 questions $(13-20 ; 22-30)$ with yes/no answers. In questions $13-20$ and 23-30, 'yes' corresponds to a score of 1 , indicating presence of stress, while 'no' corresponds to a score of 0, i.e., absence of stress. For question 22, answer 'yes' corresponds to a score of 0 , while 'no' to a score of 1 (reverse score). Total scale score may range from 0 (absence of stress) to 17 (maximum stress).

Well-being: this scale is made of 6 questions (31-36), which have two possible choices (yes/no). In questions 31 and 32 , 'yes' corresponds to a score of 1 , while 'no' corresponds to a score of 0 ; for questions 33-36, the answer 'yes' corresponds to a 0 score, while 'no' to 1 (reverse score). Total score may range from 0 to 6.

Psychological distress: the scale consists of 15 questions (37-51), with four possible choices ranging from no psychological distress to high psychological distress ('not at all', 'a little', 'somewhat', 'a great deal'). The attributable score to single items ranges from 0 to 3 , with higher scores indicating greater distress. Total score may vary from 0 to 45 . Questions $37-40$ indicate sleep disturbances and may be scored separately (range: $0-12$ ) from other questions on psychological distress (range: $0-33$ ).

Abnormal illness behavior: the scale consists of 3 questions (52-54), with four possible choices ranging from absent abnormal illness behavior to maximum ('not at all', 'a little', 'somewhat', 'a great deal'). The attributable score to single items range from 0 to 3 . Total score may vary from 0 to 9.

Quality of life: question 55 'How do you rate the quality of your life?' has 5 possible answers ('excellent', 'good', 'fair', 'poor', 'awful'). Its attributable score ranges from 4 to 0 , where 4 corresponds to 'excellent' and 0 to 'awful'. Total score may range from 0 (awful quality of life) to 4 (excellent quality of life). The scores concerned with psychological well-being (0-6) and quality of life (0-4) can also be added for obtaining a global well-being score $(0-10)$.

\section{References}

1 Sonino N, Fava GA: A simple instrument for assessing stress in clinical practice. Postgrad Med J 1998;74:408-410.

2 Feinstein AR: Clinimetrics. New Haven, Yale University Press, 1987.

3 Bech P: Clinical Psychometrics. Oxford, Wily-Blackwell, 2012.

4 Fava GA, Tomba E, Sonino N: Clinimetrics: the science of clinical measurements. Int $\mathrm{J}$ Clin Pract 2012;66:11-15.

5 Arfken CL, Balon R: Another look at outcomes and outcome measures in psychiatry. Psychother Psychosom 2014;83:6-9.

6 Shepherd A: Avoiding surrogate measures and incorporating subjective experience into clinical research. Psychother Psychosom 2014;83:119.

7 Vanheule S, Desmet M, Meganck R, Inslegers R, Willemsen J, De Schryver M, Devisch I: Reliability in psychiatric diagnosis with the DSM: old wine in new barrels. Psychother Psychosom 2014;83:313-314.

8 Grassi L, Berardi MA, Ruffilli F, Meggiolaro E, Andritsch E, Sirgo A, Caruso R, Juan Linares E, Bellè M, Massarenti S, Nanni MG; IOR-IRST Psycho-Oncology and UniFe Psychiatry Co-Authors: Role of psychosocial variables on chemotherapy-induced nausea and vomiting and health-related quality of life among cancer patients: a European study. Psychother Psychosom 2015;84:339-347.

9 Tomba E, Bech P: Clinimetrics and clinical psychometrics: macro- and micro-analysis. Psychother Psychosom 2012;81:333-343.
10 Fava GA, Ruini C, Rafanelli C: Psychometric theory is an obstacle to the progress of clinical research. Psychother Psychosom 2004;73: 145-148.

11 Kellner R: A problem list for clinical work. Ann Clin Psychiatry 1991;3:125-136.

12 Wheatley D: The stress profile. Br J Psychiatry 1990;156:658-688.

13 Ryff CD: Psychological well-being revisited: advances in the science and practice of eudaimonia. Psychother Psychosom 2014;83:1028.

14 Kellner R: Abridged Manual of the Illness Attitude Scales (Mimeographed). Albuquerque, Department of Psychiatry, University of New Mexico, 1987.

15 Sirri L, Grandi S, Fava GA: The Illness Attitude Scales. A clinimetric index for assessing hypochondriacal fears and beliefs. Psychother Psychosom 2008;77:337-350.

16 Fava GA, Guidi J, Semprini F, Tomba E, Sonino $\mathrm{N}$ : Clinical assessment of allostatic load and clinimetric criteria. Psychother Psychosom 2010;79:280-284.

17 Gill TM, Feinstein AR: A clinical appraisal of the quality of quality-of-life measurements. JAMA 1994;272:619-626.

18 Guidi J, Gambineri A, Zanotti L, Fanelli F, Fava GA, Pasquali R: Psychological aspects of hyperandrogenic states in late adolescent and young women. Clin Endocrinol 2015;83:872878.
19 Tomba E, Offidani E: A clinimetric evaluation of allostatic overload in the general population. Psychother Psychosom 2012;81:378379.

20 Offidani E, Rafanelli C, Gostoli S, Marchetti G, Roncuzzi R: Allostatic overload in patients with atrial fibrillation. Int J Cardiol 2013;165: 375-376.

21 Guidi J, Offidani E, Rafanelli C, Roncuzzi R, Sonino N, Fava GA: The assessment of allostatic overload in patients with congestive heart failure by clinimetric criteria. Stress Health 2016;32:63-69.

22 Offidani E, Ruini C: Psychobiological correlates of allostatic overload in a healthy population. Brain Behav Immun 2012;26:284-291.

23 Sonino N, Peruzzi P: A psychoneuroendocrinology service. Psychother Psychosom 2009; 78:346-351.

24 Sonino N, Ruini C, Navarrini C, Ottolini F, Sirri L, Paoletta A, Fallo F, Boscaro M, Fava GA: Psychosocial impairment in patients treated for pituitary disease: a controlled study. Clin Endocrinol 2007;67:719-726.

25 Sonino N, Navarrini C, Ruini C, Ottolini F, Paoletta A, Fallo F, Boscaro M, Fava GA: Persistent psychological distress in patients treated for endocrine disease. Psychother Psychosom 2004;73:78-83.

26 American Psychiatric Association: Diagnostic and Statistical Manual of Mental Disorders (DSM-IV). Washington, American Psychiatric Publishing, 1994. 
27 Fava GA, Freyberger HJ, Bech P, Christodoulou G, Sensky T, Theorell T, Wise TN: Diagnostic criteria for use in psychosomatic research. Psychother Psychosom 1995;63:1-8.

28 Porcelli P, Sonino N: Psychological Factors Affecting Medical Conditions. A New Classification for DSM-V. Adv Psychosom Med. Basel, Karger, 2007, vol 28.

29 Porcelli P, Guidi J: The clinical utility of the Diagnostic Criteria for Psychosomatic Research. Psychother Psychosom 2015;84:265272.

30 Mangelli L, Semprini F, Sirri L, Fava GA, Sonino N: Use of the Diagnostic Criteria for Psychosomatic Research (DCPR) in a community sample. Psychosomatics 2006; 47: 143-146.

31 Sonino N, Tomba E, Genesia ML, Bertello C, Mulatero P, Veglio F, Fava GA, Fallo F: Psychological assessment of primary aldosteronism: a controlled study. J Clin Endocrinol Metab 2011;96:E878-E883.

32 Fallo F, Barzon L, Rabbia F, Navarrini C, Conterno A, Veglio F, Cazzaro M, Fava GA, Sonino N: Circadian blood pressure patterns and life stress. Psychother Psychosom 2002;71: 350-356.

33 Rafanelli C, Offidani E, Gostoli S, Roncuzzi R: Psychological correlates in patients with different levels of hypertension. Psychiatry Res 2012;198:154-160.

34 Rafanelli C, Gostoli S, Roncuzzi R, Sassone B: Psychological correlates of vasovagal versus medically unexplained syncope. Gen Hosp Psychiatry 2013;35:246-252.

35 Kapoor WN, Fortunato M, Hanusa BH, Schulberg HC: Psychiatric illnesses in patients with syncope. Am J Med 1995;99:505512.

36 D’Antono B, Dupuis G, St-Jean K, Lévesque K, Nadeau R, Guerra P, Thibault B, Kus T: Prospective evaluation of psychological distress and psychiatric morbidity in recurrent vasovagal and unexplained syncope. J Psychosom Res 2009;67:213-222.

37 Rafanelli C, Roncuzzi R, Milaneschi Y: Minor depression as a cardiac risk factor after coronary artery bypass surgery. Psychosomatics 2006;47:289-295.
38 Rafanelli C, Roncuzzi R, Finos L, Tossani E, Tomba E, Mangelli L, Urbinati S, Pinelli G, Fava GA: Psychological assessment in cardiac rehabilitation. Psychother Psychosom 2003; 72:343-349

39 Guidi J, Rafanelli C, Roncuzzi R, Sirri L, Fava GA: Assessing psychological factors affecting medical conditions: comparison between different proposals. Gen Hosp Psychiatry 2013; 35:141-146.

40 Banihashemian K, Fakhri MK, Moazzen M: Obsessive-compulsive disorder as a risk factor in patients with implantable cardioverter defibrillator. Iran Red Crescent Med J 2011; 13:514-516.

41 Ruini C, Vescovelli F, Albieri E: Post-traumatic growth in breast cancer survivors: new insights into its relationships with well-being and distress. J Clin Psychol Med Settings 2013;20:383-391.

42 Tedeschi RG, Calhoun LG: The Post-Traumatic Growth Inventory. J Trauma Stress 1996;20:265-272

43 Fasina OF, Jonah GE, Pam V, Milaneschi Y, Gostoli S, Rafanelli C: Psychosocial effects associated with highly pathogenic avian influenza (H5N1) in Nigeria. Vet Ital 2010;46:459465.

44 Gerger H, Hlavica M, Gaab J, Munder T, Barth J: Does it matter who provides psychological interventions for medically unexplained symptoms? A meta-analysis. Psychother Psychosom 2015;84:217-226.

45 Fava GA, Bech P: The concept of euthymia. Psychother Psychosom 2016;85:1-5.

46 Ellervik C, Kvetny J, Bech P: The relationship between sleep length and restorative sleep in major depression. Psychother Psychosom 2016;85:45-46.

47 Fava GA, Guidi J, Grandi S, Hasler G: The missing link between clinical states and biomarkers in mental disorders. Psychother Psychosom 2014;83:136-141.

48 Pressman SD, Cohen S: Does positive affect influence health? Psychol Bull 2005;131:925971.
49 Fava GA: Well-Being Therapy. Treatment Manual and Clinical Applications. Basel, Karger, 2016

50 Fava GA, Sonino N: The clinical domains of psychosomatic medicine. J Clin Psychiatry 2005;66:849-858.

51 Cosci F, Fava GA, Sonino N: Mood and anxiety disorders as early manifestations of medical illness: a systematic review. Psychother Psychosom 2015;84:22-29.

52 Mechanic D, Volkart EH: Illness behavior and medical diagnoses. J Health Hum Behav 1960; 1:86-94.

53 Sirri L, Fava GA, Sonino N: The unifying concept of illness behavior. Psychother Psychosom 2013;82:74-81.

54 Evers AWM, Gieler U, Hasenbring MI, van Middendorp H: Incorporating biopsychosocial characteristics into personalized healthcare: a clinical approach. Psychother Psychosom 2014;83:148-157.

55 Cosci F, Fava GA: The clinical inadequacy of the DSM-5 classification of somatic symptom and related disorders. An alternative transdiagnostic model. CNS Spectr, in press.

56 Testa MA, Simonson DC: Assessment of quality of life outcomes. N Engl J Med 1996; 334:835-840.

57 Topp CW, Østergaard SD, Søndergaard S, Bech P: The WHO-5 Well-Being index: a systematic review of the literature. Psychother Psychosom 2015;84:167-176.

58 Bottomley A, Jones D, Claassens L: Patientreported outcomes: assessment and current perspectives of the guidelines of the Food and Drug Administration and the reflection paper of the European Medicine Agency. Eur J Cancer 2009;45:347-353.

59 Clancy C, Collins FS: Patient-Center Outcomes Research Institute: the intersection of science and health care. Sci Transl Med 2010 $2: 37 \mathrm{~cm} 18$.

60 Sechrest L: Incremental validity: a recommendation. Educat Psychol Meas 1963;23: 153-158.

61 Wise TN: Psychosomatics: past, present and future. Psychother Psychosom 2014;83:6569. 